\title{
Estudio Comparado de la Figura Electoral en Consultas Interpartidistas en Latinoamérica ${ }^{32}$
}

\author{
Comparative Study of the Electoral Figure of Interparty Consultación in Latín América \\ ${ }^{a}$ Daniel Fernando Bertel Rodríguez ${ }^{33}$, Elfa Luz Mejía Mercado ${ }^{b}$ \\ a dbertelrodriguez2@gmail.com “Semillero Políticas Públicas Participación y Desarrollo, Programa de Derecho, Universidad de \\ Cartagena. Cartagena, Colombia. \\ b dbertelrodriguez2@gmail.com Grupo de Investigación “Conflicto y Sociedad”, Universidad de Cartagena. Cartagena, Colombia.
}

Forma de Citar: D.F. Bertel-Rodríguez y E. L. Mejía-Mercado "Estudio Comparado de la Figura Electoral de las Consultas en Latinoamérica”, Rev. Saberes, Vol. 13, No. 02, pp. 46 - 56, 2020.

Recibido: 24/03/2020 Evaluación: 28/05/2020 Aceptado: 30/06/2020 DOI: https://doi.org/10.25213/1794-4384/1302.0006

\section{Resumen}

En el presente escrito se pretende hacer un estudio comparado a través de las legislaciones de países latinoamericanos con respecto a la figura electoral de la consulta interpartidista, incorporada al derecho nacional por medio del Acto Legislativo 01 de 2009, entendida esta como fenómeno independiente de la tradicional democracia intrapartidista, al intentar posicionarse en un nivel suprapartidista. Se evaluarán las características importantes que posee esta figura, sus inconvenientes y las soluciones aplicadas a estos, así como los elementos que podrían mejorar su uso con relación a sus fines en el ámbito nacional.

\section{Palabras Clave}

Partidos políticos, consultas, elecciones, interpartidismo.

\section{Abstract}

This paper intends to make a comparative study through the laws of Latin American countries towards the electoral figure of the interpartisan consultation, incorporated into national law through Legislative Act 01 of 2009, understood this as a phenomenon independent of the traditional intra-party democracy, when trying to position itself at a supra-partisan level. The important characteristics of this figure, its drawbacks and the solutions applied to them, as well as the elements that could improve its use in conection to its purposes at the national level will be evaluated.

\section{Keywords}

Political Parties, consultations, elections, interpartism.

\section{Introducción}

Sin duda, la reforma política del Acto Legislativo 01 de 2009 ha sido la última de gran impacto en el sistema político y electoral del país, definiendo junto a la Ley 1475 de 2011, parte de los lineamientos generales de la estructura democracia electoral nacional. En términos generales, la reforma, como muchas otras, ha intentado crear mecanismos que permitan en la realidad política nacional,

\footnotetext{
32 Documento de reflexión presentado en el marco del I Congreso de Investigación Científica en Ciencias Jurídicas y Económicas convocado por la Universidad Libre Sede Cartagena, Fundación Universitaria Antonio de Arévalo y otras Universidades.

33 Autor para correspondencia: correo electrónico dbertelrodriguez2@gmail.com (C) 2020 Fundación Universitaria Antonio de Arévalo - UNITECNAR. Este es un artículo bajo la licencia CC BY-NC-ND (http://creativecommons.org/licenses/by nc-nd/4.0/).
} 
reflejar o bien aparentar, una sólida democracia intrapartidista, como fórmula de consecución de una imagen de un sistema partidario robusto y participativo, y no la realidad de "vínculos políticos débiles y fluidos". (Dargent \& Muñoz, 2013).

Es común pensar en una especie de aislamiento que tiene la población en relación al sistema de partidos. La carnetización, o membresía, no parece ser una tendencia amplia en toda América Latina. Por esto, es loable buscar mecanismos que permitan la determinación de las opciones o candidatos plasmados en los tarjetones de una manera inclusiva, con la participación de simpatizantes ideológicos o el público votante general, en aras de subsanar la vacía legitimidad de decisiones de directorios o dirigentes, al menos en el nivel nacional. Se trata de un proceso que Acuña (2009) llama de descentralización de las decisiones internas de los partidos.

Fue así como surgieron en el país las consultas internas, puntualmente con el caso del partido liberal para las elecciones presidenciales de 1990, cuando Luis Carlos Galán, quien había fracasado electoralmente en sus intentos disidentes a través del Nuevo Liberalismo, condicionó su regreso al partido a la realización de dicha consulta popular, en detrimento de las tradicionales convenciones centralizadas. (Acuña, Consulta interna y democracia en los partidos políticos en Colombia: desarrollo y posibilidades, 2011, págs. 200-202).

Sin embargo, más allá de las ya tradicionales formas de democracia intrapartidista, una de las figuras electorales más innovadoras que trajo la reforma política fue la consagración de las consultas interpartidistas para la provisión de candidaturas uninominales. De esta manera, partidos pueden agruparse para la convocatoria a una consulta con el objetivo de determinar, dentro de las opciones que acuerden, cuál será el candidato o formula que tal agremiación presentará al evento electoral. Este tipo de consulta se desmarca conceptualmente de las tradicionales consultas intrapartidistas o internas, las cuales han sido ampliamente estudiados en el país, siendo entonces que como instrumento democrático estas consultas tienen unos elementos compositivos que las hacen particulares, por lo que su estudio resulta pertinente.

Corresponde a este escrito la caracterización cuales son los mecanismos semejantes consagrados en las normas de otros países latinoamericanos, así como su impacto en las elecciones.

\section{Metodología}

La presente investigación, de carácter comparativo, busca caracterizar descriptivamente la figura electoral de las consultas interpartidarias en América Latina, determinando los elementos que determinan la esencia, fines e impacto de las mismas. Por esto, esta investigación será cualitativa, con base en la revisión del contenido normativo nacional e internacional relacionado con la figura bajo estudio, sus fines y elementos, la revisión de fuentes de información secundaria como libros o artículos científicos vinculados, así como información de la prensa escrita.

Como primera medida de la investigación se procurará entender cuál es el marco normativo que regula la figura en el territorio nacional, y cómo esta ha funcionado materialmente. Posteriormente, se evaluarán las normativas de tres países que poseen figuras esencialmente similares en sus normativas, con el objetivo de comparar sus elementos y funcionamiento en la realidad. A partir de esto, se ofrecerán las consideraciones importantes en materia del futuro de esta figura y su sostenibilidad.

\section{Resultados}

\section{Las Consultas Interpartidistas en Colombia}

La consagración de los mecanismos democráticos de consultas está expresa en la Carta, más específicamente en el articulado introducido por el Acto Legislativo 01 de 2009, que modificó el artículo 107 de la Constitución, donde en uno de sus apartes 
reza: "Para la toma de sus decisiones o la escogencia de sus candidatos propios o por coalición, podrán celebrar consultas populares o internas o interpartidistas que coincidan o no con las elecciones a Corporaciones Públicas, de acuerdo con lo previsto en sus Estatutos y en la ley.

En el caso de las consultas populares se aplicarán las normas sobre financiación y publicidad de campañas y acceso a los medios de comunicación del Estado, que rigen para las elecciones ordinarias. Quien participe en las consultas de un partido o movimiento politico o en consultas interpartidistas, no podrá inscribirse por otro en el mismo proceso electoral. El resultado de las consultas será obligatorio". (Constitución Política de Colombia, 1991).

Más adelante, la Ley 1475 de 2011 se encargaría en su artículo quinto de desarrollar los conceptos relacionados con las consultas ${ }^{34}$. Conviene entonces detenerse en el análisis de estos. Lo primero es la distinción de los fines de las consultas. Sobre esto, se tiene que existen consultas con propósitos de tomar decisiones internas, como lo pueden ser la adopción de estatutos o principios, o bien la elección de directivas o cargos al interior de los partidos, casos que ya cuentan con antecedentes históricos en el país (MOE, 2017) y la escogencia de candidatos a elecciones populares.

Siguiendo, está luego una distinción que Acuña (2011) llama de forma. Así, existen las consultas que las normas llaman "internas" y las "populares". Las primeras son aquellas en las cuales solo participan los miembros de la organización política convocante, es decir, quienes están en su registro de afiliados. En

34 ARTÍCULO 5o. Las consultas son mecanismos de participación democrática y política que los partidos y movimientos políticos con personería jurídica, y/o grupos significativos de ciudadanos pueden utilizar con la finalidad de adoptar decisiones internas o escoger sus candidatos, propios o de coalición, a cargos o corporaciones de elección popular.

Las consultas pueden ser internas o populares. Se denominarán internas cuando en ellas sólo puedan participar los miembros de la organización política que se encuentren en el registro de afiliados. Se denominarán populares cuando puedan hacerlo todos los ciudadanos inscritos en el censo electoral. Las consultas internas se regularán por las disposiciones previstas en los estatutos de los partidos y movimientos políticos. este tipo de consultas, las regulaciones para su puesta en marcha están sujetas a las disposiciones estatutarias respectivas del partido o movimiento convocante, teniendo estas sus ventajas cualitativas. Como indica Acuña (2009):

también pueden optar legitimamente por reservar el "derecho de admisión" a sus decisiones, es decir, realizar sus propias consultas, a puerta cerrada, este es un mecanismo, que ha sido eficaz para ellos, al impedir que algún ciudadano que no se encuentre afiliado o no pertenezca a la colectividad, tenga voz y menos voto, dentro de las decisiones que sólo competen al partido, esta modalidad tiene la virtud de colocar la decisión dentro del núcleo del partido, buscando fortalecer su estructura interna. (pág. 158)

De otro lado, las consultas populares son aquellas en las que pueden participar todos los ciudadanos inscritos en el censo electoral, tengan o no probada afiliación partidista. Naturalmente por esta dimensión amplísima, se rigen por las normas aplicables a las elecciones ordinarias. Por las confusiones que podría causar el término "consulta popular" con la figura democrática independiente que tiene la Constitución, Acuña sugiere usar indistintamente el nombre "consulta interna", distinguiendo más bien, si está es cerrada o abierta, según fuere el caso.

Por último, y cómo distinción más importante para este caso, se encuentra la resultante entre las consultas propias de partidos y las interpartidistas. En estas últimas, según la ley, debe mediar un acuerdo previo suscrito por las directivas del nivel respectivos de sendas

Las consultas convocadas por una coalición de partidos y/o movimientos políticos con personería jurídica, pueden ser internas o populares y se denominarán interpartidistas. Podrán ser convocadas con el objeto de seleccionar candidatos de coalición a cargos uninominales, previo acuerdo suscrito por sus directivos nacionales o departamentales según sea el caso.

El Estado contribuirá al financiamiento de las consultas mediante el sistema de reposición de gastos por votos obtenidos. Los partidos y movimientos políticos podrán solicitar anticipos para estas consultas de acuerdo con la reglamentación que expida el Consejo Nacional Electoral. 
agrupaciones políticas. Estas consultas tendrían el fin de elegir un candidato de coalición para la provisión de cargos uninominales, sean alcaldes, gobernadores o la Presidencia de la República.

Se puede dilucidar que para las consultas interpartidistas existe una especie de doble instancia de elección. Primeramente, cada partido, movimiento o grupo significativo de ciudadanos elige a su postulación, usando los mecanismos internos que sus estatutos particulares les permitan. Teniendo ya cada uno su precandidato, someten a consulta estos nombres para obtener un único candidato, bajo el entendido del compromiso de todas las agrupaciones a apoyar al ganador, además de la prohibición de apoyar o inscribir a un candidato distinto ${ }^{35}$. Estas consultas pueden ser internas o populares, entendiendo como participantes en las primeras, los miembros totales de los partidos o movimientos coaligados, debiendo existir claridad en el acuerdo de las directivas en las normas a aplicar.

Desde la intuición, se tiene que la primera dificultad que podría tener la figura viene desde el punto de vista de la disparidad o de capacidad, que estructuralmente, podrían tener los partidos coaligados. Por un lado, en las consultas internas partiría con especial ventaja de mayorías el partido que tuviese mayor cantidad de inscritos en el registro de afiliados. Esto per se, junto a factores de fidelidad partidaria, haría difícil encontrar que esta

\footnotetext{
${ }^{35}$ Ley 1475 de 2011- ARTÍCULO 7o. OBLIGATORIEDAD DE LOS RESULTADOS. El resultado de las consultas será obligatorio para el partido, movimiento, grupo significativo de ciudadanos o coalición, que las hubiere convocado, así como para los precandidatos que hubieren participado en ellas.

Se entiende que un precandidato ha participado en una consulta cuando su inscripción ha quedado en firme de conformidad con las disposiciones establecidas por los partidos y movimientos que las convocan. Quienes hubieren participado como precandidatos quedarán inhabilitados para inscribirse como candidatos en cualquier circunscripción dentro del mismo proceso electoral, por partidos, movimientos, grupos significativos de ciudadanos o coaliciones distintas. Los partidos y movimientos políticos y sus directivos, las coaliciones, los promotores de los grupos significativos de ciudadanos y los precandidatos que participaron en la consulta, no podrán inscribir ni apoyar candidatos distintos a los
}

figura fuere llamativa para su puesta en práctica.

Y del lado de las consultas populares, siendo que podría haber mayor número de simpatizantes que en el registro, además de factores como la popularidad personalista de un candidato, o la amplitud de los sectores sociales que representan, podrían existir desequilibrios. Pero en todo caso, parece mucho más razonable el sometimiento que un partido realizaré a su precandidato, ya fuere como medición o prueba de las posibilidades en elección general o la legitimidad en una franja ideológica entre los simpatizantes de los partidos coaligados.

En aras de garantizar condiciones paritarias para los partidos participantes de las coaliciones para las consultas populares, la ley 1475 de 2011 dispuso: "En el caso de las consultas populares interpartidistas, el límite de gastos, el número de vallas, avisos en prensa y cuñas, se fijarán para cada partido, movimiento o grupo significativo de ciudadanos en condiciones de igualdad, los cuales harán la distribución entre sus precandidatos".

\section{Impacto de la Consulta Interpartidista en Colombia}

El uso más importante que se le ha dado a la figura en la nación desde que existe, fue para la escogencia de candidatos presidenciales para las Elecciones del año 2018. Se realizaron dos consultas en el mismo día de elecciones de Congreso, de las cuales resultaron elegidos quienes a la postre se enfrentaron en la

seleccionados en dicho mecanismo, con excepción de los casos de muerte o incapacidad absoluta del candidato así seleccionado. La inobservancia de este precepto, será causal de nulidad o revocatoria de la inscripción del candidato que se apoye, diferente al elegido en la consulta. La inscripción, en todo caso, a solicitud del candidato seleccionado, se hará a nombre de los partidos, movimientos o coaliciones que realizaron la consulta, aunque no suscriban el formulario de solicitud de inscripción.

En caso de incumplimiento de los resultados de las consultas o en caso de renuncia del candidato, los partidos, movimientos y/o candidatos, deberán reintegrar proporcionalmente los gastos en que hubiere incurrido la organización electoral, los cuales serán fijados por el Consejo Nacional Electoral con base en los informes que presente la Registraduría Nacional del Estado Civil. Estas sumas podrán ser descontadas de la financiación estatal que corresponda a dichos partidos y movimientos. (Ley Estatutaria 1475, 2011) 
segunda vuelta electoral, Iván Duque y Gustavo Petro. Desde el primer momento que se supo de la realización de las consultas, la opinión pública no dudó en señalar lo que sería su verdadero fin: no saldar democrática y convenientemente una disputa en un sector ideológico en aras de un mejor desempeño electoral, sino medir fuerzas con la votación obtenida, como golpe mediático y argumento electoral. (Semana, 2018).

La primera de las dos consultas, y la más votada, fue la Gran Consulta por Colombia, que integró al candidato del Centro Democrático, Iván Duque, quien obtuvo 4’044.509 votos, Marta Lucía Ramírez, por el Grupo Significativo Por una Colombia Honesta y Fuerte, obteniendo 1'538.882 votos, y por el Grupo Significativo La Patria de Pie, Alejandro Ordóñez, quien quedó en último lugar con 385.110 votos. Hubo en total una participación del $16,82 \%$ del personal habilitado para votar en el país, 6’138.503 votos. (Registraduría Nacional del Estado Civil, 2018)

La otra consulta, la Consulta Inclusión Social por la Paz, enfrentó a solo dos candidatos: Gustavo Petro, avalado por el Movimiento Alternativo Indígena $\mathrm{y}$ por su Grupo Significativo, Colombia Humana, quien se impuso con 2'853.731 votos, frente a Carlos Caicedo, del Grupo Significativo Fuerza Ciudadana, quien solo alcanzó 515.309 votos. En total, participó el 9,67\% de la población habilitada para votar, siendo $3^{\prime} 531.288^{36} \mathrm{de}$ personas. (Registraduría Nacional del Estado Civil, 2018)

La primera consulta agrupó a la derecha del espectro político nacional, mientras que la segunda formó a dos de las principales tendencias en la izquierda. No se puede decir que hubiese una marcada heterogeneidad en ambas consultas. Es importante señalar aquí, como factor común a los participantes de estas consultas, el hecho de que, salvo el caso de Iván Duque, todos fueron avalados o coavalados por Grupos Significativos de Ciudadanos. Estas son agrupaciones políticas creadas con un propósito coyuntural: las elecciones, por lo que dista del factor de permanencia de los partidos.

El uso de este tipo de organización supone una ventaja en varios aspectos. Lo primero es que están usualmente formados alrededor de una figura política conocida, una persona que considera tener la capacidad de movilizar masas por fuera de las estructuras y jerarquías partidistas. Es una vertiente más cercana al personalismo, que a la asunción de la afinidad ideológica o programática con los lineamientos o dirigencia de un partido. Es, sin duda, un espacio más flexible, más cuando se trata de una elección uninominal. Además de esto, cuenta con la ventaja de no comprometer nada más allá que al candidato mismo. Perder la consulta para Iván Duque, hubiese representado la imposibilidad para su partido de presentar un candidato, caso que no se replicaría para sus oponentes. Véase con respecto de esto, que tanto Marta Lucía Ramírez como Alejandro Ordóñez han sido siempre miembros del partido Conservador, pero decidieron apartarse del directorio de su partido en busca de la candidatura por la consulta.

Debe señalarse, por último, que al nivel regional no ha habido mayor uso de la figura, como lo muestra la última elección. (Lewin, 2019)

\section{Las Consultas Interpartidistas en Latinoamérica}

Para este apartado se definió el estudio de tres países Sudamericanos: Argentina, Chile y Perú. Su elección obedece a varios factores, como su filiación regional, la pluralidad en sus sistemas partidistas, su relativa estabilidad democrática $\mathrm{y}$, principalmente, que consagran en sus legislaciones mecanismos electorales esencialmente similares a las consultas interpartidistas: la confrontación entre precandidatos de varios partidos para obtener una nominación conjunta.

\footnotetext{
${ }^{36}$ Esta cifra incluye los votos no marcados y los nulos
} 


\subsection{Argentina}

En Argentina no existe la figura de las consultas interpartidistas de la misma manera que en Colombia, pero si hay un proceso de similar esencia con matices distintos. Para empezar, debe entenderse que, por su carácter federal, sus normas del sistema de partidos (no existe requisito de umbral para las personerías jurídicas), así como una tradición histórica, el sistema político es bastante fraccionado: existen muchos partidos. Esto conlleva a que sean frecuentemente usadas las alianzas electorales o confederaciones de partidos (Clerici, 2015), que junto con los partidos políticos, son agrupados bajo el concepto de agrupaciones políticas ${ }^{37}$.

La Ley nacional 26.571 de 2009 creó lo que para este estudio es relevante: las elecciones Primarias, Abiertas, Simultáneas y Obligatorias (PASO, por sus siglas). Estas elecciones se llevarían a cabo, como su nombre lo indica, simultáneamente en toda la nación y con la participación abierta (en similitud al carácter de las consultas populares en Colombia), y es por medio de las cuales se definirían cuales agrupaciones políticas podrían participar en las elecciones nacionales, dependiendo de la cantidad de votos obtenidos en sus consultas, así como la determinación de cuál lista de candidatos representaría a la agrupación. Los cargos incluirían desde niveles de distrito, así como el legislativo nacional, y la presidencia y vicepresidencia de la República, y todas las

\footnotetext{
37 ARTICULO 18. - Entiéndese por agrupaciones políticas a los partidos políticos, confederaciones y alianzas participantes en el proceso electoral. En adelante, se denomina elecciones primarias a las elecciones primarias abiertas, simultáneas y obligatorias. (Ley 26.571, 2009)

38 ARTICULO $6^{\circ}$ - Modificase el artículo 10 de la Ley Orgánica de los Partidos Políticos, 23.298, el que queda redactado de la siguiente manera:

Artículo 10: Los partidos políticos de distrito y nacionales pueden constituir alianzas de distrito o nacionales respectivamente de dos (2) o más partidos, de acuerdo a lo que establezcan sus respectivas cartas orgánicas, con el propósito de presentar candidatos para cargos públicos electivos.

Asimismo, los partidos de distrito que no formen parte de un partido nacional pueden integrar una alianza con al menos un (1) partido político nacional.
}

agrupaciones políticas que deseen aspirar a estos cargos deben presentarse a las primarias. Así pues, las alianzas son conformadas por medio de un acuerdo que deben asentir las dirigencias de los partidos ${ }^{38}$, no existiendo regulación especial para propugnar por la igualdad de los partidos dentro de la alianza, sino que estos tienen mayor margen de autonomía en la definición del acuerdo. De esta manera, las alianzas, antes de poder ir a las elecciones nacionales, deben participar obligatoriamente del proceso de primarias como alianza, por lo que cada partido puede presentar sus precandidatos a ser sometidos al voto popular o abierto. Cada partido podría incluso presentar varios precandidatos

No es una opción, como ocurre en Colombia, donde los partidos deben medir las ventajas o no de llevar a cabo este proceso o con la posibilidad de hacerlo internamente, sino que es obligatorio y abierto. El hecho de que sea simultaneo añade variables que lo hacen intrigante desde el punto de vista político, pues la confrontación entre distintas alianzas bien puede que sea más vistoso que los enfrentamientos internos propiamente dichos. El fenómeno se magnifica cuando se constata que el número de alianzas para aspirar al cargo de presidente, es cada vez más alto, y a su vez, las alianzas tienen más partidos integrantes. (Clerici, 2015).

Sin embargo, en lo que al impacto de la figura se refiere, siendo que se evalúa el fenómeno de consulta interpartidista en cargos uninominales, no ha sido importante. Si se toma en cuenta las últimas elecciones PASO

Los partidos políticos que integren la alianza deben requerir su reconocimiento, ante el juez federal con competencia electoral del distrito respectivo o de la Capital Federal, en el caso de las alianzas nacionales, hasta sesenta (60) días antes de la fecha de la elección primaria, abierta, simultánea y obligatoria, debiendo acompañar:

a) El acuerdo constitutivo de la alianza, que incluya el acuerdo financiero correspondiente;

b) Reglamento electoral;

c) Aprobación por los órganos de dirección de cada partido, de la formación de la alianza transitoria de acuerdo a sus cartas orgánicas;

d) Domicilio central y actas de designación de los apoderados; e) Constitución de la junta electoral de la alianza;

f) Acuerdo del que surja la forma en que se distribuirán los aportes correspondientes al fondo partidario permanente. (Ley $26.571,2009)$ 
en 2019, presentaron listas al cargo de Presidencia diez (10) alianzas (Cámara Nacional Electoral, 2019), pero en ningún caso hubo competencia interna, pues fueron listas únicas provenientes de acuerdos anteriores entre los partidos de las alianzas, donde progresivamente precandidatos fueron retirando sus candidaturas. Al final, aunado a que cada ciudadano solo puede votar una vez, las elecciones solo sirvieron como anticipo y tamizaje (por el umbral) para las elecciones oficiales dos meses después con idéntico resultado: la victoria del Frente de Todos de Alberto Fernández y Cristina Fernández.

\subsection{Chile}

En este país existe un sistema de elecciones primarias, regulado por la ley 20.640 , para las nominaciones de candidatos a presidente de la república, parlamentarios, gobernadores regionales y alcaldes. Estas elecciones pueden ser convocadas bien por partidos políticos individualmente o por pactos electorales entre varios partidos y candidatos independientes ${ }^{39}$. Este mecanismo, a diferencia del caso argentino, y en similitud al colombiano, no es obligatorio, y responde entonces a las consideraciones de conveniencias y razonamientos políticos, plasmados en el pacto electoral ${ }^{40}$. Tal circunstancia generó

39 Artículo 8.- Los partidos políticos podrán participar en la elección primaria para la nominación de candidatos a los cargos de presidente de la república, de gobernador regional y de alcaldes, en forma individual o en conjunto con otros partidos y candidatos independientes conformando un pacto electoral, y con el objeto de nominar un candidato para cada cargo en el territorio electoral que corresponda. (...) (Ley 20.640, 2012)

${ }^{40}$ Artículo 13.- El pacto electoral para la elección de presidente de la república deberá formalizarse ante el director del servicio electoral, antes del vencimiento del plazo para efectuar las declaraciones de candidaturas de las elecciones primarias, mediante la presentación de los siguientes documentos:

18. a) Declaración suscrita por los presidentes y secretarios de los partidos políticos y por los independientes integrantes del pacto, que deberá indicar la decisión de concurrir en pacto electoral para la elección primaria de presidente de la república, de apoyar en la elección definitiva al candidato que resulte nominado de este proceso y las demás exigencias señaladas en el inciso cuarto del artículo 4 de la ley $\mathrm{N}^{\circ} 18.700$.

19 . b) Declaración de las candidaturas para la nominación al cargo de presidente de la república para la elección primaria. (Ley 20.640, 2012)

41 Artículo 21.- Cada partido político o pacto electoral que participe en las elecciones primarias, deberá presentar al Servicio Electoral para cada tipo de primarias, ya sea presidencial, parlamentarias, de gobernador regional o de polémica en las discusiones en el Congreso, como lo señala González \& Vargas (2013):

"El carácter voluntario de las elecciones primarias no estuvo exento de debates en el Congreso, ya que hubo varios parlamentarios que sostuvieron durante toda la discusión de la ley que las elecciones primarias debian ser de carácter obligatorio, ya que sólo a través de un sistema de elecciones primarias obligatorias sería posible hacer frente a la crisis de representatividad existente”. (pág. 115)

La ley no impone a su vez, como si lo hace en el caso argentino, cual es el mecanismo de la elección. Lo que si hace es delimitar las opciones en cuanto a quienes pueden participar en la consulta, que pueden elegir el partido o pacto electoral. Las opciones ${ }^{41}$ son amplias pues dependen de varias variables, como si es de un partido individual, o si se trata de un pacto, o si existen candidatos independientes. En cualquier caso, el SERVEL ${ }^{42}$ es quién organiza la elección, por lo que aplican las normas electorales ordinarias en materia de competencia leal $y$ en condiciones de igualdad.

Para el caso de este estudio, es importante observar las opciones para los pactos electorales. Allí se tienen las contenidas en los literales c, d y e del artículo 21 de la ley. El primero sería lo que en Colombia se

alcaldes, junto con la declaración de candidaturas, la norma de cómo se determinará el padrón electoral de los electores habilitados para sufragar en cada una de ellas.

La norma deberá contemplar una de las siguientes opciones de electores:

a) Sólo los afiliados al partido habilitados para ejercer el derecho a sufragio, en el caso que el partido participe en forma individual.

b) Sólo los afiliados al partido, e independientes sin afiliación política, habilitados para ejercer el derecho a sufragio, en el caso que el partido participe en forma individual.

c) Sólo los afiliados al partido o a los partidos integrantes del pacto habilitados para ejercer el derecho a sufragio, en el caso de un pacto electoral.

d) Sólo los afiliados al partido o a los partidos integrantes del pacto e independientes sin afiliación política habilitados para ejercer el derecho a sufragio, en el caso de un pacto electoral. e) Todos los electores habilitados para sufragar.

En el caso de elecciones primarias para Presidente de la República o gobernador regional en que exista una candidatura independiente según la forma señalada en el inciso final del artículo 8, los partidos políticos o pactos electorales participantes del proceso sólo podrán elegir como norma para determinar el padrón electoral las contenidas en las letras b), d) o e) del presente artículo. (Ley 20.640, 2012)

${ }^{42}$ Servicio Electoral de Chile 
consideraría una consulta interna o cerrada, donde solo participarían los afiliados de los partidos del pacto. El literal e equivaldría a una consulta popular. La novedad sería la posibilidad consagrada en el literal d, donde se delimita la elección a los afiliados a los partidos del pacto y a los independientes sin afiliación política, es decir, a quienes no pertenezcan a otros partidos.

Esta opción, que no está consagrada en Colombia, es más que razonable, inicialmente por la consagración de que los independientes (que serían parecidos a los candidatos por Grupos Significativos) pueden estar en pactos, y obviamente el grueso de sus seguidores no tendría afiliación partidista. Además, se minimizaría la posibilidad de influencia de agentes políticos distintos o hasta contrarios, en la toma de la decisión. En Colombia, los candidatos por grupos significativos de ciudadanos solo podrían aceptar razonablemente una consulta abierta, pues la otra opción, cerrada, es altamente inconveniente o imposible. Un punto medio es entonces loable.

Otro punto a considerar, es que las elecciones a un mismo cargo se realizan simultáneamente. Por último, la norma consagra los efectos vinculantes de la elección, delimitando que sus resultados deben ser acatados por los partidos del pacto y los independientes, que no podrán postular otro nominado al mismo cargo, consagrando excepciones a esta regla apenas lógicas como el fallecimiento del ganador $u$ otras. Es importante considerar que la coalición queda así constituida, de manera que publicitariamente el ganador usa los logos, lemas y nombre de la misma. González \& Vargas (2013) explican:

"Las elecciones primarias se caracterizan por ser de carácter irreversibles. Esto significa que si voluntariamente un partido o pacto decide definir sus candidaturas a través de elecciones primarias, basta que ese candidato gane por un voto para que sea el candidato oficial, anulándose la reversibilidad del proceso de primarias". (págs. 114-115)
En Chile se le ha dado uso a esta figura desde su creación. Recientemente se puede reseñar las elecciones primarias del año 2017, donde fue usada por dos pactos electorales. El primero fue el pacto Chile Vamos, que reunió a sectores de centro derecha chilena, juntando a los partidos Unión Demócrata Independiente, Renovación Nacional, Evolución Política y Partido Regionalista Independiente, más independientes. Hubo tres candidatos, Sebastián Piñera, a la postre ganador de la primaria y de la elección posterior, que se presentó como independiente pero fue apoyado por el RN, la UDI y el PRI, Felipe Kast por Evópoli, y Manuel Ossandón, independiente.

La otra coalición fue el Frente Amplio, de centro izquierda, donde se enfrentaron Beatriz Sánchez, quien se presentó como independiente pero con el apoyo de la mayoría de partidos del pacto y que ganaría abrumadoramente y Alberto Mayol, también independiente, que recibió el apoyo del Partido Igualdad. Ambas coaliciones tuvieron las primarias simultáneamente como indica la norma, por lo que cada ciudadano solo podía votar en una consulta. Luego, tendrían buenos desempeños en la primera vuelta los ganadores, quedando en primer y tercer lugar respectivamente, ganando Piñera el ballotage contra Alejandro Guillier que se postuló a través de su partido sin el uso de este mecanismo de primarias.

\subsection{Perú}

El Congreso peruano recientemente aprobó una nueva legislación sobre democracia interna de los partidos, la ley 30.998 de 2019. Esta reforma incluyó un sistema de Elecciones Primarias para la provisión de los cargos a presidente de la república, representantes ante el congreso, gobernadores y alcaldes, inspirado en el sistema argentino. Estas elecciones serían de manera simultánea, con voto universal, libre, obligatorio, igual, directo y secreto, siendo elecciones abiertas para los afiliados o no a los partidos, como lo que serían las consultas populares en Colombia. 
Como en el caso argentino, existe la figura dentro del sistema político de las Alianzas entre organizaciones políticas, dispuesta en el artículo 15 de la ley 28.094 de $2003^{43}$, constituidas según este por un acuerdo que exige varios puntos de compromiso, así como según el artículo 13b de la misma disposición, de obtener victoria electoral la alianza debe permanecer por lo menos por el periodo correspondiente. Siendo esas las condiciones, las alianzas de organizaciones políticas pueden realizar las primarias entre sus precandidatos. Las primarias imponen un umbral para la participación en la elección posterior, idéntico al argentino, pero imponiendo una condición más gravosa a las alianzas, lo cual podría desincentivar su uso extensivo ${ }^{44}$.

Por la naturaleza del sistema político peruano, no existe posibilidad de vinculación de candidatos independientes a las alianzas y elecciones primarias, por cuanto se obliga la filiación partidista a la hora de participar. La norma no estipula expresamente las consecuencias vinculantes de las elecciones, solo se limita a establecerlas como condición para obtener la candidatura, por lo que no se descartarían retiros o alianzas posteriores. En todo caso, estarían estas decisiones sujetas al marco de las posibilidades que permitiese la alianza particular y su pacto.

En la organización de estas elecciones participan tres organismos del Estado peruano,

43 Artículo 15. Alianzas entre organizaciones políticas Las organizaciones políticas inscritas pueden hacer alianzas entre ellas, bajo una misma denominación y símbolo común, para poder participar en cualquier tipo de elección popular. La alianza debe inscribirse en el Registro de Organizaciones Políticas. Para su inscripción, la alianza presenta el acta de constitución correspondiente y su reglamento electoral. El acta debe contener, además, el proceso electoral en el que se participa; los órganos de gobierno y sus miembros; la denominación, el símbolo y domicilio legal; la declaración expresa de objetivos y los acuerdos que regulan el proceso de democracia interna conforme a ley; la definición de los órganos o autoridades que toman las decisiones de índole económicofinanciera y su relación con la tesorería de la alianza; la designación de los personeros legales y técnicos de la alianza, la designación del tesorero y de los tesoreros descentralizados que tienen a su cargo la ejecución de las decisiones económicofinancieras, la forma de distribución del financiamiento público directo que le corresponda a la alianza; $y$, en caso de disolución, a los partidos que la conforman. Para participar en el proceso electoral, la alianza debe solicitar y lograr su inscripción en el Registro de Organizaciones Políticas conforme al calendario el Registro Nacional de Identificación y Estado Civil, que crea el padrón electoral, la Oficina Nacional de Procesos Electorales, que organiza las elecciones y el Jurado Nacional Electoral, que fiscaliza y resuelve los conflictos electorales (Ley 30.998, 2019). Esto garantiza las condiciones electorales ordinarias para los participantes.

Dado que se trata de una normatividad relativamente nueva, no ha habido ocasión aun para su puesta en práctica, que debería ser para las elecciones generales de 2021, pero por medio de la misma ley se creó un régimen especial de transición para los partidos actuales de cara a esa elección, por lo que su experimentación práctica deberá esperar aún un tiempo.

\section{Discusión y Conclusiones}

De la observancia comparada se pueden establecer varias conclusiones relevantes. Lo primero es el carácter pionero de la legislación colombiana estableciendo la figura de la consulta interpartidista como modelo autónomo. Sin embargo, cabe destacarse una diferenciación con respecto a cómo se presenta en otros países: en los países estudiados, más que el foco apuntaré a la constitución de la consulta, existen regulaciones más importantes en el tema de la alianza en sí.

Luego, la consulta o elección es un derivado de una alianza que subsiste usualmente más

electoral establecido para tales fines. Las organizaciones políticas que integren una alianza no pueden presentar, en un mismo proceso electoral, listas de candidatos distintas de las presentadas por la alianza. (Ley 28.094, 2003)

${ }^{44}$ Artículo 24. Modalidad de las elecciones primarias. -

Las elecciones primarias se realizan de manera simultánea mediante voto universal, libre, obligatorio, igual, directo y secreto de todos los ciudadanos, estén o no afiliados a una organización política.

Para continuar con su participación en el proceso electoral, el partido político debe obtener al menos el $1,5 \%$ de los votos válidamente emitidos en las elecciones primarias.

Para el caso del movimiento regional, debe obtener al menos el $4 \%$ de los votos válidamente emitidos en las elecciones primarias de su circunscripción.

De existir alianza electoral, los porcentajes referidos se incrementan en $0,5 \%$ por cada organización política adicional. (Ley $30.998,2019$ ) 
allá de la consulta. Solo basta mirar el hecho de que todos los países tienen legislación acerca de estas alianzas, debiendo establecerse personas jurídicas independientes, un reglamento interno o hasta el nombramiento de cargos, logos y emblemas. Incluso en el caso peruano, se impone legalmente el subsistir de la alianza en caso de triunfo, al menos por el periodo de mandato.

Este hecho permite incluso que el instrumento no solo se use en la provisión de nominaciones a cargos uninominales, sino que también para la provisión de coalición a parlamentos y corporaciones, cosa que no sucede aquí en Colombia. Este hecho, junto con la simultaneidad electoral general, parece impulsar la formación de fuertes alianzas, con partidos más comprometidos con las mismas.

En el caso argentino, las alianzas van simultáneamente también a las elecciones legislativas nacionales, siendo entonces actores como tal el parlamento, lo que inspira un aire de permanencia democrática más que coyuntural. Entre tanto, en Chile pueden existir alianzas disimiles tanto para las elecciones presidenciales como para las parlamentarias. El reto entonces para la legislación nacional sería cómo establecer unas exigencias concretas de unidad manifiesta en acuerdo entre las agrupaciones políticas a realizar consulta interpartidista.

Una característica positiva del sistema de consultas nacional es el carácter opcional de uso, pues no está claro de los ejemplos internacionales usados, que la obligatoriedad pueda ser positiva o que verdaderamente logre los efectos deseados en materia de democracia interpartidaria (el caso argentino sustenta puntualmente esto), aunque valdría la pena sondear si esto provocaría una mayor tendencia a las coaliciones o fusiones de partidos en busca de mayores réditos electorales.

Uno de los elementos más relevantes a destacar es la opción de padrones electorales dispuestas en la legislación chilena, donde se incluye la posibilidad de que en la consulta no participen personas afiliadas a partidos políticos distintos a aquellos del pacto electoral. Aunque con los niveles de afiliación a los partidos que hay en el país, esto no tendría mayor impacto, podría generar más confianza interpartidaria sobre el resultado.

Por otra parte, la legislación nacional, quizás por el carácter coyuntural que les da a las consultas, es un poco más explícita en cuanto a las normas para la garantía en materia de campaña: financiación y publicidad entre los partidos de la consulta, como limite a las dificultades que plantea el desequilibrio entre los participantes. El resto de los países dejan esto en manos de la regulación ordinaria. Sin embargo, esto no ha servido de a mucho a motivar la participación de partidos políticos en estas, en cambio, su uso ha sido mayor para los Grupos Significativos de Ciudadanos.

También debería pensarse una escala múltiple de consultas, reguladas, donde los grupos políticos en su interior a través de una consulta cerrada determinaran sus precandidatos, para luego ser llevados a las consultas populares, cosa que no se contempla en ninguna legislación revisada.

Por último, se destaca el hecho de que el impacto de las consultas interpartidistas, si bien no está probado que sean positivas de cara a la elección oficial, tampoco se demostrado que sea negativo como el mismo caso colombiano demuestra y ratifica el caso chileno, donde el desempeño electoral posterior fue superlativo por parte de quienes usaron el mecanismo. Esta figura puede que sea, si fuere usada de la manera más eficaz e inspirada en sus fines, un instrumento suprapartidista renovador del sistema político nacional.

\section{Referencias Bibliográficas}

Acuña, F. (2009). Partidos políticos y procesos de selección interna de candidatos en Colombia. Revista Análisis político (66), 145 161.

Acuña, F. (2011). Consulta interna y democracia en los partidos políticos en Colombia: desarrollo y posibilidades. Controversia, 195-219.

Cámara Nacional Electoral. (2019). ACORDADA EXTRAORDINARIA 
NÚMERO SESENTA Y UNO de 2019. Buenos Aires. Obtenido de https://www.electoral.gob.ar/nuevo/paginas/p df/AE_61_19.pdf

Clerici, P. (2015). La creciente importancia de las alianzas electorales en un escenario de competencia territorializada. El caso argentino. Revista SAAP, 9(2), 11-41.

Constitución Política de Colombia. (20 de Julio de 1991). Gaceta Constitucional No. 116 de 20 de julio de 1991. Bogotá D.C.: Asamblea Nacional Constituyente de 1991.

Dargent, E., \&amp; Muñoz, P. (2013). ¿Democracia contra partidos? Desinstitucionalización del sistema de partidos en Colombia. Politai: Revista de Ciencia Política (Versión original en inglés publicada en el Journal of Politics in Latin América 3, 2, 43-71), 4(7), 51-72.

González, C., \&amp; Vargas, I. (2013). Memoria para optar por el grado de Licenciado en Ciencias Jurídicas: Génesis y análisis jurídico de la ley No 20.640, que establece el sistema de elecciones primarias para la nominación de candidatos a presidente de la república, parlamentarios, y alcaldes. Santiago de Chile: Universidad de Chile, Facultad de Derecho.

Lewin, J. (12 de abril de 2019). Las consultas interpartidistas no pegaron. La silla vacía. Obtenido de https:/lasillavacia.com/lasconsultas-interpartidistas-no-pegaron-71079

Ley 20.640. (29 de noviembre de 2012). Establece el sistema de elecciones primarias para la nominación de candidatos a presidente de la república, parlamentarios y alcaldes.

Diario Oficial. Santiago de Chile: Congreso Nacional de Chile. Obtenido de http://bcn.cl/1uw1z

Ley 26.571. (14 de diciembre de 2009). Ley de democratización de la representación política, la transparencia y la equidad electoral. Buenos Aires: Congreso de la Nación Argentina.
Ley 28.094. (01 de noviembre de 2003). Ley de partidos políticos. Diario Oficial El Peruano del sábado 01 de noviembre de 2003. Lima: Congreso de la República del Perú.

Ley 30.998. (27 de agosto de 2019). Ley de por la que se modifica la ley 28094 , ley de organizaciones políticas, para promover la participación política y la democracia en las organizaciones políticas. Diario Oficial El Peruano. Lima: Congreso de la República del Perú.

Ley Estatutaria 1475. (14 de Julio de 2011). Por la cual se adoptan reglas de organización $\mathrm{y}$ funcionamiento de los partidos $\mathrm{y}$ movimientos políticos, de los procesos electorales y se dictan otras disposiciones. Diario Oficial No. 48.130 del 14 de Julio de 2011. Bogotá D.C., Colombia: Congreso de la Republica.

MOE. (2017). Informe consultas internas de partidos políticos 2000-2018. Bogotá. Obtenido de: https://moe.org.co/wpcontent/uploads/2017/11/Informe-consultasinternas-de-Partidos-Poli\%CC\%81 tico-2018limpio.pdf

Registraduría Nacional del Estado Civil. (2018). Consulta Inclusión Social por la Paz. Bogotá. Obtenido de https://elecciones.registraduria.gov.co:81/elec 20180311/resultados/htmlfijo/consulta.html Registraduría Nacional del Estado Civil. (2018). Gran Consulta por Colombia. Bogotá. Obtenido de: https://elecciones.registraduria.gov.co:81/elec 20180311/resultados/htmlfijo/consulta.html

Semana. (10 de marzo de 2018). El verdadero mano a mano en las consultas. Obtenido de https://www.semana.com/confidenciales/artic ulo/el-verdadero-mano-a-mano-en-lasconsultas/559774 